\title{
Gamification in thoracic surgical education: Using competition to fuel performance
}

\author{
Nahush A. Mokadam, MD, Richard Lee, MD, MBA, ${ }^{\mathrm{b}}$ Ara A. Vaporciyan, MD, ${ }^{\mathrm{c}}$ Jennifer D. Walker, MD, ${ }^{\mathrm{d}}$ \\ Robert J. Cerfolio, MD, MBA, ${ }^{\mathrm{e}}$ Joshua L. Hermsen, MD, ${ }^{\mathrm{a}}$ Craig J. Baker, MD, ${ }^{\mathrm{f}}$ Rebecca Mark, MBA, ${ }^{\mathrm{g}}$ \\ Lauren Aloia, BS, ${ }^{g}$ Dan H. Enter, MD, ${ }^{\text {h }}$ Andrea J. Carpenter, MD, ${ }^{i}$ Marc R. Moon, MD, ${ }^{j}$ \\ Edward D. Verrier, MD, ${ }^{a}$ and James I. Fann, $\mathrm{MD}^{\mathrm{k}}$
}

\begin{abstract}
Objectives: In an effort to stimulate residents and trainers to increase their use of simulation training and the Thoracic Surgery Curriculum, a gamification strategy was developed in a friendly but competitive environment.

Methods: “Top Gun.” Low-fidelity simulators distributed annually were used for the technical competition. Baseline and final video assessments were performed, and 5 finalists were invited to compete in a live setting from 2013 to 2015. "Jeopardy." A screening examination was devised to test knowledge contained in the Thoracic Surgery Curriculum. The top 62 -member teams were invited to compete in a live setting structured around the popular game show Jeopardy.
\end{abstract}

Results: "Top Gun." Over 3 years, there were 43 baseline and 34 final submissions. In all areas of assessment, there was demonstrable improvement. There was increasing evidence of simulation as seen by practice and ritualistic behavior. "Jeopardy." Sixty-eight individuals completed the screening examination, and 30 teams were formed. The largest representation came from the second-year residents in traditional programs. Contestants reported an average in-training examination percentile of 72.9. Finalists reported increased use of the Thoracic Surgery Curriculum by an average of 10 hours per week in preparation. The live competition was friendly, engaging, and spirited.

Conclusions: This gamification approach focused on technical and cognitive skills, has been successfully implemented, and has encouraged the use of simulators and the Thoracic Surgery Curriculum. This framework may capitalize on the competitive nature of our trainees and can provide recognition of their achievements. (J Thorac Cardiovasc Surg 2015;150:1052-8)

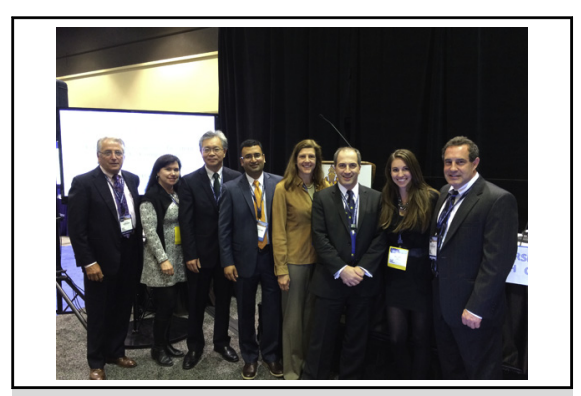

Authors E.V., R.M., J.F., N.M., J.W., A.V., L.A., R.C. (not pictured: R.L., J.H., C.B., D.E., A.C., M.M.)

\section{Central Message}

Focused on technical and cognitive skills, gamification may capitalize on the competitiveness of our trainees to fuel performance.

\section{Perspective}

In an effort to stimulate residents and trainers to increase their use of simulation training and the Thoracic Surgery Curriculum, a gamification strategy was developed. Focused on technical and cognitive skills, this has encouraged the use of simulators and the Thoracic Surgery Curriculum. This framework may capitalize on the competitive nature of our trainees to improve their performance.

See Editorial Commentary page 1059.

See Editorial page 1038.
Thoracic surgical education has undergone a fundamental transformation in the past several years. Our profession has faced internal and external challenges, including duty-hour restrictions, generational expectations, competing interests

From the a Division of Cardiothoracic Surgery, University of Washington, Seattle,

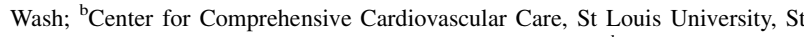
Louis, Mo; ${ }^{\mathrm{c}}$ M.D. Anderson Cancer Center, Houston, Tex; ${ }^{\mathrm{d}}$ Heart and Vascular Center of Excellence, University of Massachusetts, Worcester, Mass; ${ }^{\mathrm{e}} \mathrm{Section}$ of Thoracic Surgery, University of Alabama-Birmingham, Birmingham, Ala; ${ }^{\mathrm{f}} \mathrm{Car}-$ dioVascular Thoracic Institute, University of Southern California, Los Angeles, Calif; ' ${ }^{\mathrm{g} J o i n t}$ Council on Thoracic Surgery Education, Inc, Chicago, Ill; ${ }^{\mathrm{h}}$ Division of Cardiac Surgery, Northwestern University, Chicago, Ill; ${ }^{\mathrm{i}}$ Division of Thoracic Surgery, University of Texas-San Antonio, San Antonio, Tex; ${ }^{j}$ Division of Cardiothoracic Surgery, Washington University School of Medicine, St Louis, Mo; and ${ }^{\mathrm{k}}$ Department of Cardiothoracic Surgery, Stanford University, Stanford, Calif. in our educators, increased public scrutiny on outcomes, and a declining pass-rate on the board examination. ${ }^{1-4}$ In response, thoracic surgical organizations established the Joint Council on Thoracic Surgery Education, Inc (JCTSE)

\footnotetext{
This work was funded by the American Association for Thoracic Surgery Graham Foundation, and an unrestricted educational grant from Ethicon, Inc, Somerville, NJ.

Received for publication May 22, 2015; revisions received July 2, 2015; accepted for publication July 19, 2015; available ahead of print Aug 25, 2015.

Address for reprints: Nahush A. Mokadam, MD, Cardiovascular Surgery, University of Washington Medical Center, 1959 NE Pacific St, Box 356310, Seattle, WA 98195 (E-mail: mokadamn@uw.edu).

0022-5223/\$36.00

Copyright (C) 2015 by The American Association for Thoracic Surgery

http://dx.doi.org/10.1016/j.jtcvs.2015.07.064
} 


\section{Abbreviations and Acronyms \\ AATS = American Association for Thoracic Surgery \\ ABTS = American Board of Thoracic Surgery \\ ACGME $=$ Accreditation Council for Graduate Medical Education \\ ITE $=$ In-Training Examination \\ JCTSE $=$ Joint Council on Thoracic Surgery Education \\ SESATS $=$ Self-Education Self-Assessment in Thoracic Surgery \\ STS = Society of Thoracic Surgeons \\ TSC = Thoracic Surgery Curriculum \\ TSDA = Thoracic Surgery Directors Association \\ TSRA $=$ Thoracic Surgery Residents Association}

in $2008 .^{5}$ The mission of JCTSE is to advance thoracic surgical education by revising and upgrading the educational systems in our specialty. Efforts by the JCTSE have been innovative and include the development of learning and content management systems, resident course curricula, technical and cognitive simulation, and, importantly, faculty training as educators. Further, the JCTSE developed and implemented a new Thoracic Surgery Curriculum (TSC) in 2010, which was made available via an online learning and content management system in 2013.

Key concepts in our educational system have been identified that may benefit from a "new look." For many years, the acquisition of technical and cognitive skills for the cardiothoracic surgery trainee was not constrained by the restriction of hours in the hospital. In the past decade, the advent of work-hour restrictions has had a measurable effect on thoracic surgery training. ${ }^{6,7}$ Further, general surgery training historically provided predictable exposure to vascular surgery and cardiothoracic surgery. The endovascular approach to vascular disease and the attrition of cardiothoracic surgery rotations nationwide has further eroded the development of open surgical skills, critical to training in our specialty. Currently, more than $80 \%$ of general surgery residents seek additional training, leading to an increasingly top-heavy system, and one in which more junior-level operative exposure is limited. ${ }^{8,9}$ These issues in part have led to the development of the integrated cardiothoracic residency, which remains a work in progress.

In an effort to stimulate residents and trainers to increase their use of simulation training and the TSC, a gamification approach in a friendly but competitive environment was proposed. Gamification is a process by which users are encouraged and enticed to perform tasks by incorporating elements of game design. ${ }^{10}$ Gamification has been successfully used in a multitude of health care initiatives with success. ${ }^{10,11}$ As has been done in the research environment, technical and cognitive challenges were devised to heighten the awareness of all aspects of thoracic surgical education. In this study, we report the development of our gamification strategy, the competitions, and the impact of such an approach.

\section{METHODS}

The institutional review board at the University of Washington granted an educational waiver for analysis of these activities. In addition to distribution of simulators by the Thoracic Surgery Directors Association (TSDA), financial support for these contests was sought from several sources, including in-kind grants from industry, unrestricted educational grants from industry, support from the American Association for Thoracic Surgery (AATS) Graham Foundation, and support from the JCTSE for conduct of the skills and cognitive assessments, onsite competitions, and subsequent data analysis.

\section{"Top Gun"}

In the past 3 years, the TSDA distributed a low-fidelity coronary anastomosis simulator (Chamberlain Group, Great Barrington, Mass) to all first-year cardiothoracic residents in traditional 2- and 3-year training programs. An instructional video and a validated assessment form were included. ${ }^{12,13}$ The methodology for the "Top Gun" competition has been previously described. ${ }^{14}$ Notifications were sent to all program directors and coordinators by JCTSE, and to all thoracic surgery residents by the Thoracic Surgery Residents Association (TSRA). An announcement was present on the TSC homepage in 2015, and during resident events at the Society of Thoracic Surgeons (STS) 51st annual meeting. All first-year traditional-track (2- or 3-year) residents were invited in 2013 and 2014; fourth-year integrated residents and residents from Canadian programs also were invited in 2015. Participation was voluntary. Briefly, residents were asked to submit an anonymous baseline performance of an end-to-side coronary anastomosis using 4-mm synthetic vessels to a secure online Web site. Program directors assigned a faculty mentor to coach the resident in his or her performance. After a period of training, the residents submitted a final performance of the anastomosis. The same 3 judges completed all the evaluations in a blinded fashion. The top 5 performers were invited to participate in a live competition at the AATS annual meeting, which was the venue in each of the past 3 years.

At the AATS annual meeting, during the welcome reception in the exhibit hall, each resident was provided a private table, with video broadcast of their performance on monitors in the room. Three judges trained in technical skills assessment completed the evaluations. Audience members were able to directly observe the performances, or view them on a video screen. The best performer was awarded the "Top Gun" prize.

\section{"Jeopardy"}

In an attempt to foster the use of the TSC, a cognitive competition was conceived. A screening examination was developed using the TSC learning management system. A 60-item examination, consisting of 25 cardiovascular, 25 thoracic, and 10 congenital questions, was derived from the question bank of more than 1500 questions. All Accreditation Council for Graduate Medical Education (ACGME)approved thoracic surgery residents in any year of training (integrated or traditional-track) were invited to participate, whereas advanced trainees in congenital heart, intensive care, or non-ACGME fellowships were excluded. Contestants had 20 minutes to complete the quiz, and were asked to identify an individual a priori with whom to create a 2 member team from a single institution. Notifications were sent to all program directors and coordinators by JCTSE and to all thoracic surgery residents by the TSRA. An announcement was present on the TSC homepage in 2015, and during resident events at the STS 51st annual meeting. Participation was voluntary, and the screening examination was anonymous. Each institution could have multiple teams, 
and no individual could participate in more than 1 team. A pretest survey was administered, which identified year of training, program type, most recent TSDA In-Training Examination (ITE) score, gender, age, marital status, number of years at current program, subspecialty track, study habits, and preparation for the contest. Over the course of 1 week during which the quiz was available, all contestants completed the quiz, and their score was combined with their teammate's score. The top 62 -member teams were invited to participate in a live competition at the 95th AATS annual meeting.

For the competition, novel questions were written by the organizing committee, sourced directly from the TSC. They were organized by topic, and entered into a freely available, interactive game board mimicking Jeopardy. The top 6 2-member teams were divided into 2 groups ranked by their performance on the screening examination. The competition was held interspersed throughout the 95th AATS annual meeting in the exhibit hall. Special audiovisual accommodations were required for a game board and a separate score board managed by 2 separate computers. Onsite management included a moderator, a game-board coordinator, a score keeper, a buzzer controller, and 2 judges. Each 3-team group entered a live semifinal round consisting of 25 questions divided into 5 categories. The winner of each round participated in a live final round (Figure 1), consisting of 25 questions divided into 5 categories, followed by a final single question. This process culminated in the "Jeopardy" champion.

\section{RESULTS}

In 2013, the "Top Gun" competition was supported by an unrestricted educational grant from Ethicon, Inc (Somerville, NJ). In 2015, the small-vessel anastomosis simulators distributed by TSDA were supported by an in-kind donation from Medtronic, Inc (Minneapolis, Minn). In 2014 and 2015, the AATS Graham Foundation provided educational grants to support resident travel and accommodations for both competitions. For all years, the JCTSE provided supplementary funding for all the events.

\section{"Top Gun"}

Over the course of 3 years, there have been 43 baseline video submissions and 34 final video submissions, along with 15 finalists. Results from 2013 have been previously

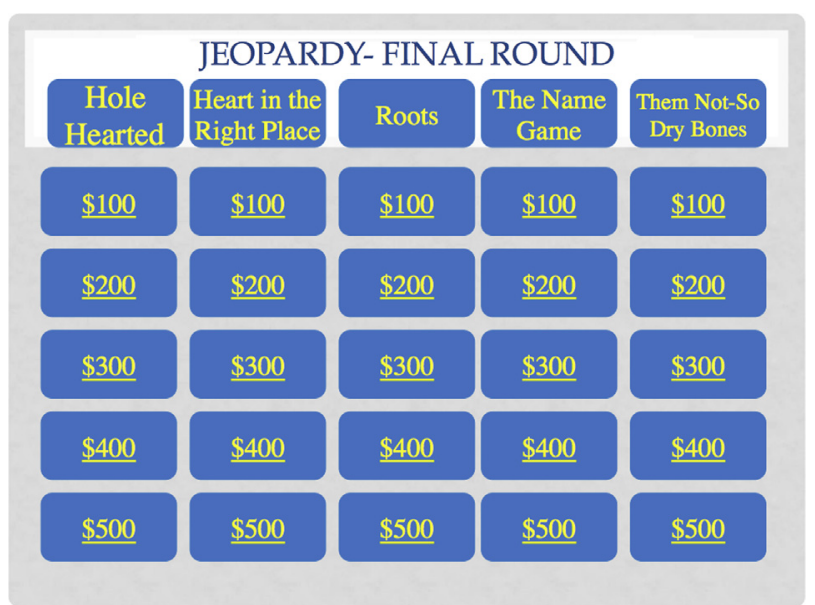

FIGURE 1. Game board from "Jeopardy" competition. Five topics with 5 questions each were organized with ascending monetary values for each round.

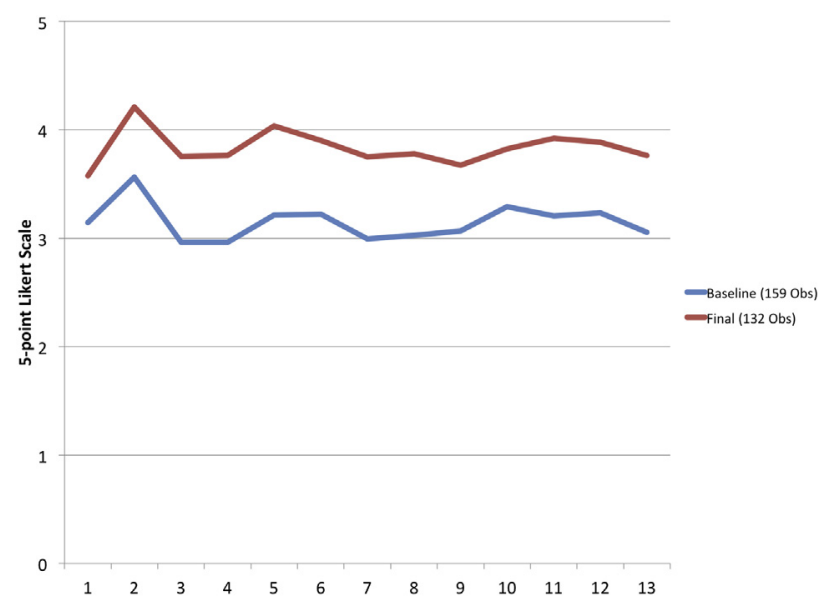

FIGURE 2. Performance assessment for "Top Gun" baseline and final video submission. Improvement noted in all areas of assessment, using a validated assessment tool. ${ }^{13} 1$, Arteriotomy; 2, Graft orientation; 3, Bite; 4, Spacing; 5, Needle holder use; 6 , Use of forceps; 7, Needle angles; 8 , Needle transfer; 9, Suture management; 10, Knot tying; 11, Hand mechanics; 12 , Use of both hands; 13 , Economy of time.

reported in detail. ${ }^{14}$ In 2013, there were 17 baseline and 15 final submissions, in 2014 there were 12 baseline and 12 final submissions, and in 2015, there were 24 initial and 17 final submissions. In Figure 2, results of performance on the 13-point video-based assessment are depicted. In all areas of assessment, there was an improvement from baseline to final submission.

Residents were asked to perform a baseline anastomosis before any practice on the simulator. In 2013 and 2014, contestants apparently complied with this instruction. Interestingly, in 2015, several of the residents had completed anastomoses on the baseline submission video, indicating that they had practiced (Figure 3). Because the qualifying submission was the final submission, residents were still permitted to participate. Additionally, due to the announcements in 2015, the organizing committee received requests from Canadian residents to participate in the contest, which was permitted.

The live competition held during the AATS annual meeting in 2013 to 2015 has gained considerable attention

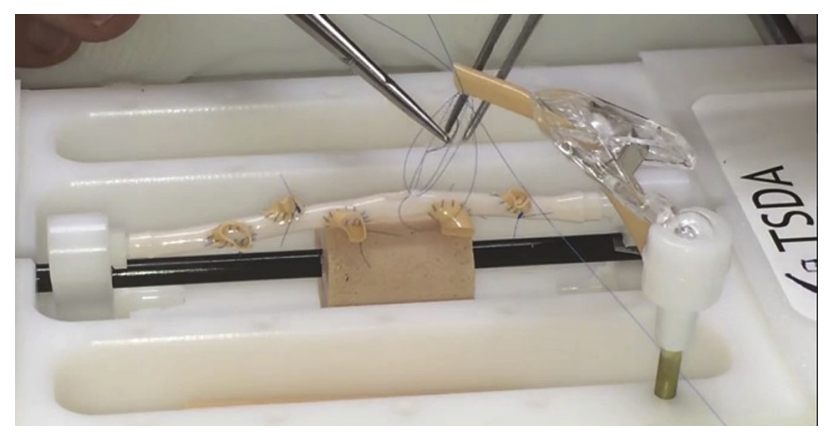

FIGURE 3. Practice before baseline. Several residents completed anastomoses before submitting a baseline performance. 


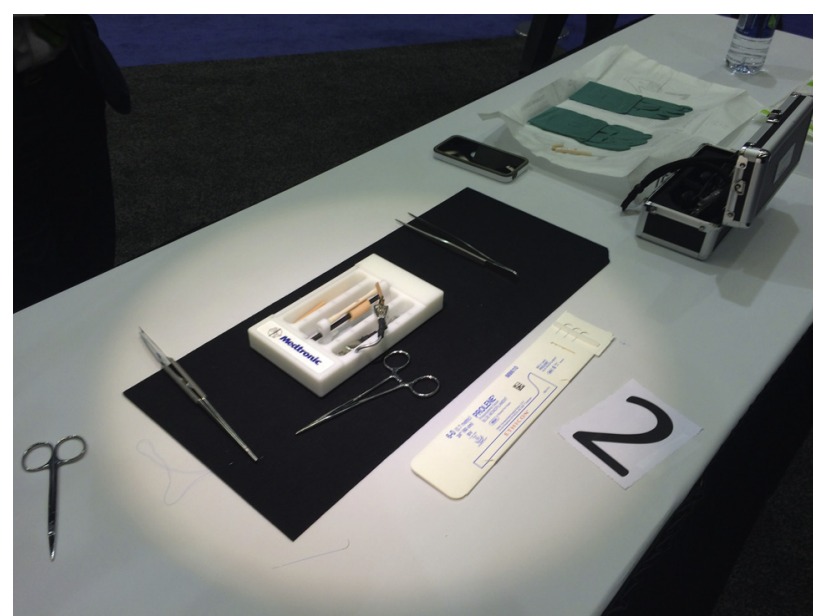

FIGURE 4. Ritual behavior by a finalist during live competition. This resident brought a nonslip, antiglare mat, instruments, and arranged the equipment deliberately.

over the years. The finalists appeared well prepared, and many of them were observed performing rituals consistent with warm-up (Figure 4). A number of high-stakes behaviors have been observed by contestants, including perspiration, tremor, and suture entanglement. The anastomosis was judged by quality before time. In all years, the level of competition was high, requiring close inspection of opened anastomoses by the judges to determine the champion (Figure 5). The live competitions were well attended by physicians, residents, industry partners, and societal leadership.

\section{"Jeopardy"}

A total of 68 individuals completed the online screening examination and attendant survey; 8 individuals did not

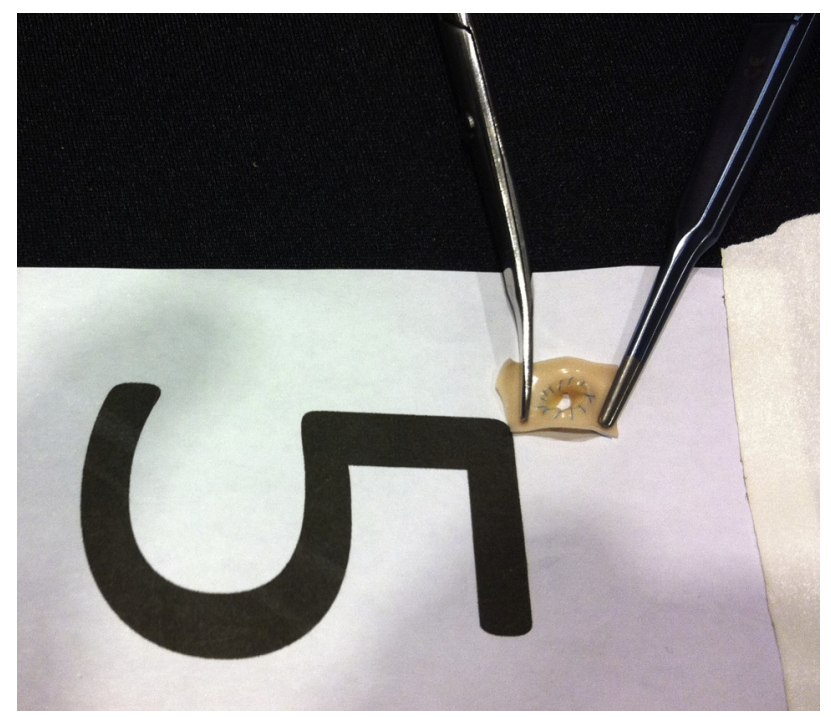

FIGURE 5. Open anastomosis examination by judges during final competition. Careful attention could be paid to bite size and spacing, as well as overall anastomotic configuration. have a teammate complete the examination, thus producing a total of 30 complete teams. The contestants had the largest representation from second-year residents in a traditional program, but also had a reasonable distribution of residents from other levels (Figure 6). Twenty-six contestants were from integrated programs, 18 were from 2-year traditional programs, 14 were from 3-year traditional programs, and 10 were from 4-3 "fast-track" programs. The average age of the residents was 32.6 years (range 27-37), 19\% were women, 59\% were married, and $25 \%$ were "thoracic" track training.

The random quiz deployed by the learning management system was easily accessible to the contestants. There were multiple complaints lodged by the contestants that the quiz was "impossible" and "unfair." Because we required a priori selection of teammates, there was a bell-shaped curve for both individual and team scores (Figure 7). It is also probable that because of the timelimited nature of the screening examination, contestants were not able to participate due to competing interests, such as clinical care.

Survey results revealed the majority learned of this competition from their program director $(56 \%)$, whereas others were informed by another resident $(16 \%)$, the JCTSE Web site $(12 \%)$, the STS Resident Luncheon $(4 \%)$, the AATS Web site $(3 \%)$, and others not specified $(9 \%)$. Most residents (93\%) said that they did not prepare additionally for the pretest. On average, these contestants used the TSC learning management system 2.8 hours per week. They also used a multitude of other sources, including textbooks, online resources, journals, and Self-Education SelfAssessment in Thoracic Surgery (SESATS) as part of their routine study habits. When asked if they would prepare additionally for the competition if selected as a finalist, the residents reported they would add 9.9 hours per week, 4.5 hours per week of which would be for team training. The resident contestants also self-reported their most recent ITE results, with an average percentile of 72.9 (Figure 8). The finalists had an average ITE percentile of 81.8 compared with 70.8 for the rest of the participants.

The live competitions were well attended. Audience participation was brisk, with friendly promotion and sparring. The contestants exhibited many signs of high-stakes competition, and handled themselves admirably. The final round was extremely engaging, and was decided by the final question.

\section{DISCUSSION}

Simulation training has become a requirement for certification by the American Board of Thoracic Surgery (ABTS). ${ }^{15}$ Studies have examined the role of simulation training in cardiothoracic surgery, many of which have demonstrated a measurable benefit. ${ }^{16-20}$ The use of simulation among training programs has varied 
Post-Graduate Year Distribution

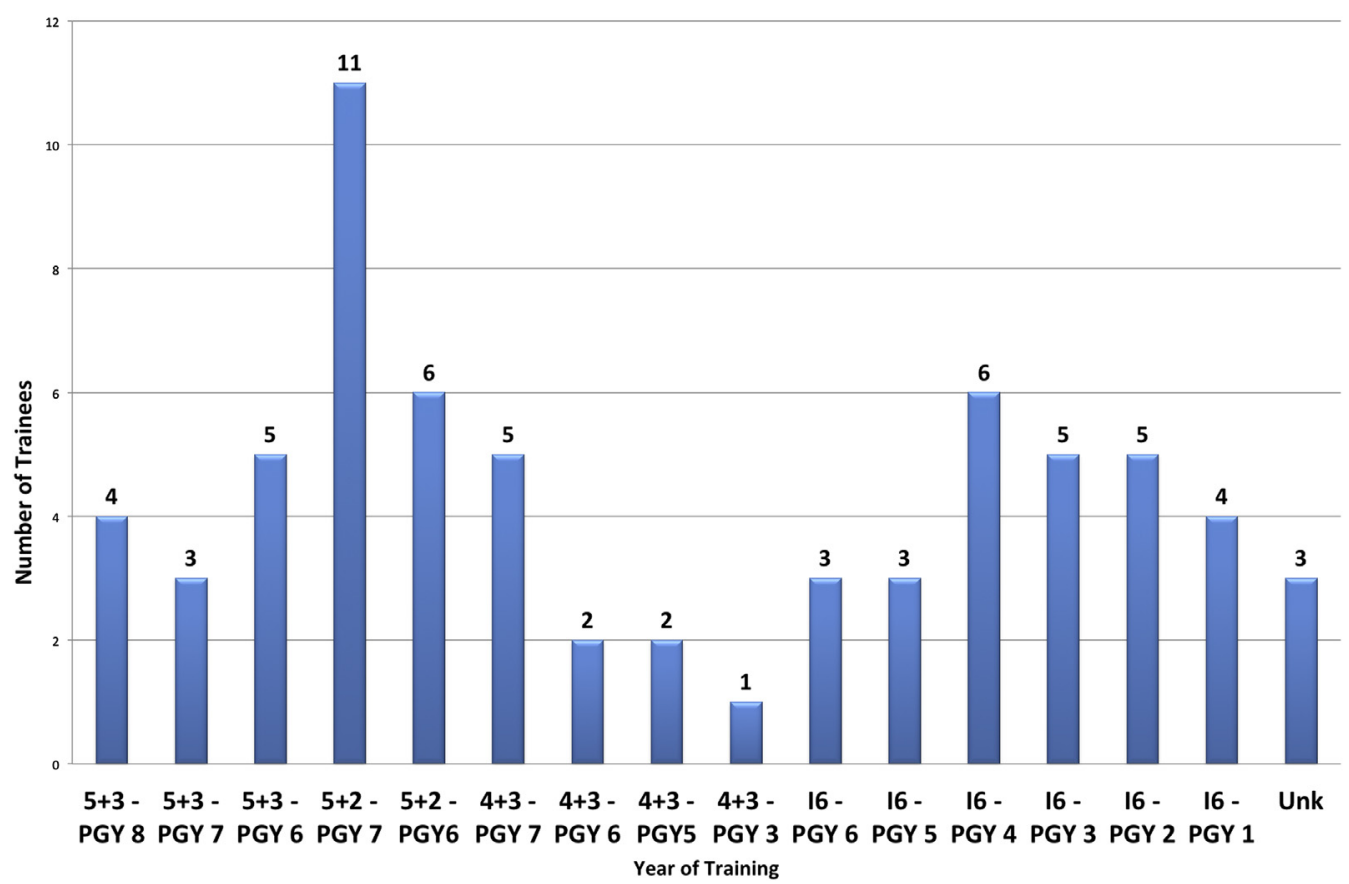

FIGURE 6. Postgraduate year distribution of participants for online screening examination. Unk, Unknown; $P G Y$, postgraduate year.

considerably, and a standard approach has not been fully implemented. Nonetheless, increasing the awareness and usage of simulation remains a goal of many surgical educators.

Simultaneously, JCTSE was charged with the development of the TSC, which would consolidate the requisite knowledge base and provide guidance to the learner and educator. ${ }^{5}$ Further, the intent of the TSC was to provide a basis for formative and summative high-stakes examinations, such as the ITE and the ABTS qualifying and certifying examinations. Incorporated into this curriculum are peer-reviewed materials housed in a content management system, case-based discussions, quizzes, and relevant articles. Developed several years ago, the curriculum has undergone its first complete revision in 2015. Like simulation training, the adoption of this curriculum has been variable among programs. Currently, the TSC platform does not have individual usage data available for analysis. Recognition of this deficit has prompted a revision in the software platform to accommodate more granular analysis of TSC usage.

Like many specialties and domains, the members of the thoracic surgery community are well known for their competitive spirit. All major meetings have inclusive resident poster competitions, several paper competitions, and highly coveted research awards. Over the past several
Pre-Test Score Distribution

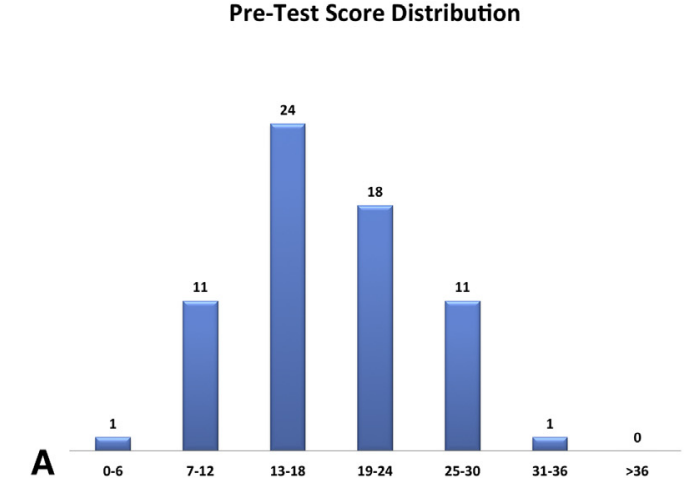

Team Score Distribution

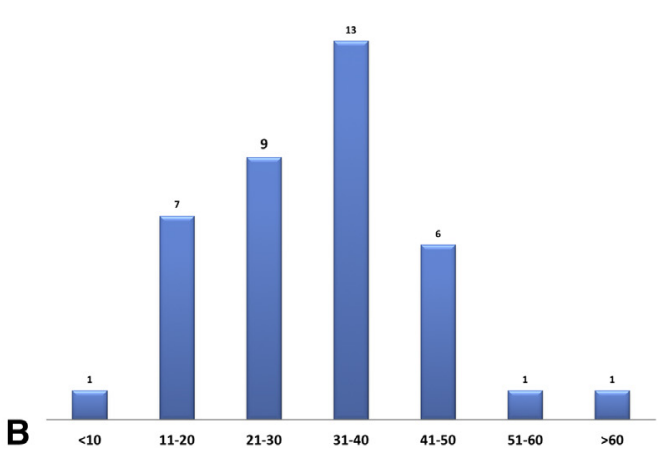

FIGURE 7. A, Pretest score distribution. The raw scores of the contestants are shown (of a total of 60 questions). B, Team score distribution. The combined raw scores of the teams are shown. The top 6 teams were invited to the final competition. 


\section{ITE Score Distribution Percentile}

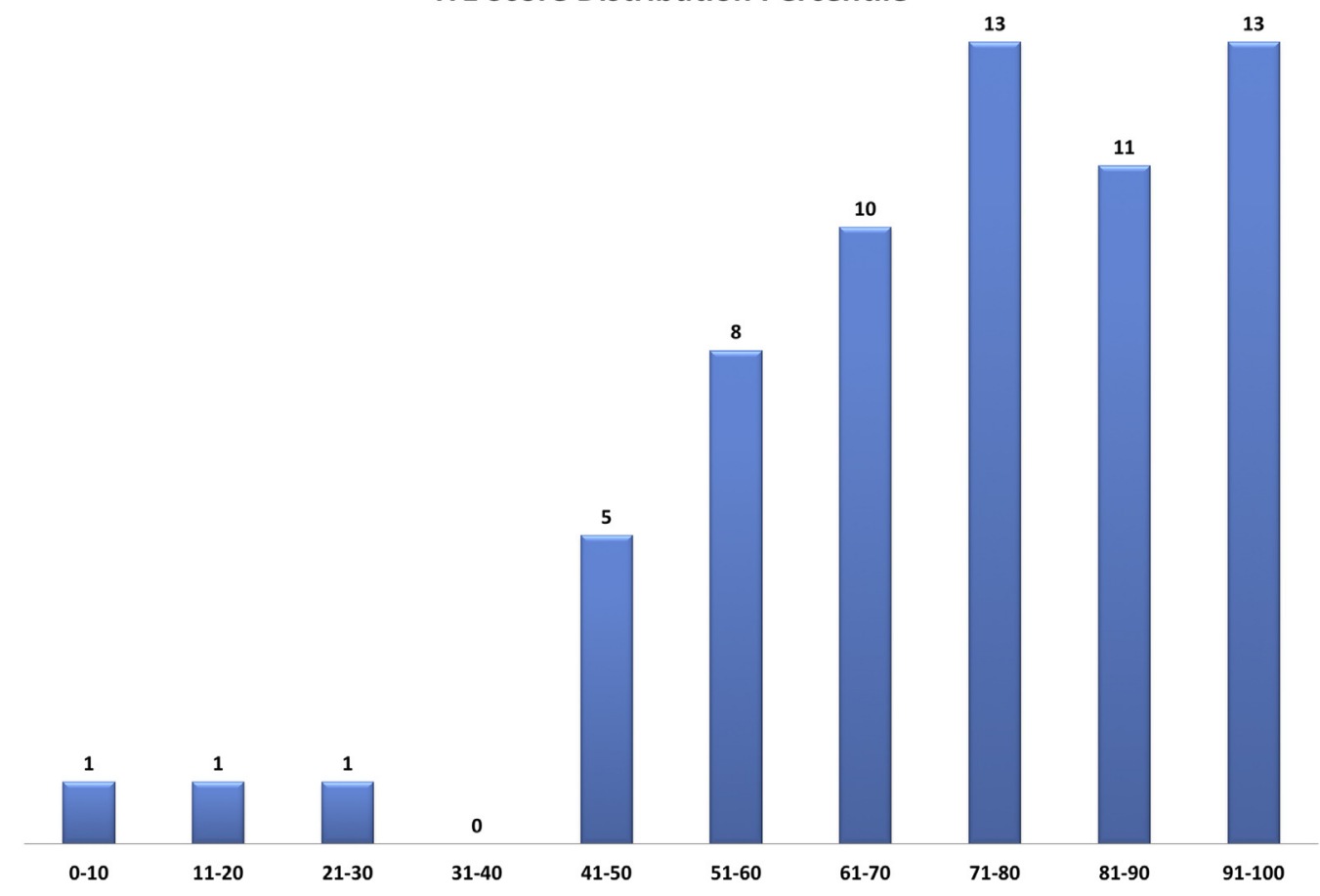

FIGURE 8. Self-reported ITE score. The national median is 50th percentile. ITE, In-Training Examination.

years, our specialty continues to develop engaging technical and cognitive events and exercises to foster enthusiasm and to enhance motivation in trainees and teachers. These events have the potential to encourage training programs to produce the best research, technical skills, and cognitive accomplishments.

The TSDA Boot Camp, now in its eighth year, has provided early resident exposure and faculty education predicated on simulation-based learning. ${ }^{18}$ At the same time, the JCTSE Educate-the-Educators course, now in its sixth year, has been developed and implemented to augment the trainers' knowledge in modern education theory. Both of these efforts seek to raise the bar in educational awareness for the thoracic surgery community, and in both of these settings, the public exposure of the educator and the learner to the training process has highlighted the need for educational improvement in our specialty.

Gamification in education is a well-established concept. ${ }^{10,11,14}$ It is one tool or strategy to better motivate our residents to practice and study, recognizing that there are other methods for motivation as well. Because some of our trainees have difficulty with high-stakes examinations, many educators have proposed various strategies to broaden the exposure of our trainees to relevant content (ie, TSC) and motivating them to use such content. Many residents in thoracic surgery have appeared to respond favorably to the challenges put forth by these competitions based on gamification. From the technical skills perspective, there has been an increasing interest in
"Top Gun" over the years and an increased use of simulation-based learning at many residency programs. "Jeopardy," in its inaugural year, was also met with enthusiasm and excitement from the thoracic surgery community. Despite criticism from the residents regarding the difficulty of the screening examination, this deliberately difficult examination provided sufficient discrimination by which to choose the 6 final teams (Figure 7, B). Most notably, for both contests, contestants reported that they prepared considerably, with deliberate practice for "Top Gun" and by increased use of the TSC for "Jeopardy."

It may be reasonable to assume that residents (and program directors) may have self-selected contestants for these competitions, as evidenced by the relatively high baseline scores for "Top Gun" and the high ITE scores for "Jeopardy" contestants. Not surprisingly, there is also a correlation between higher baseline ITE scores and the chance of reaching the finals in this type of competition. It is our responsibility to ensure that residents at all levels and abilities are encouraged, but not required to compete. The gamification methodology may not be applicable to all learners, and does not supplant lifelong learning strategies. Also, gamification, as used in this study, is an external form of motivation, and clearly the residents involved are highly internally motivated as well. It is the internal motivation that all educators are trying to identify and bring forth from our trainees. Investigation of other novel educational paradigms that appeal to other (and all) types of learners remains an ongoing effort. This report 
demonstrates that gamification has been able expose residents to the principles put forth by these competitions: with deliberate practice, technical performance can be increased, and with curricular study, cognitive performance can be improved.

\section{Limitations}

Although simulation-based learning has been used to augment technical skills training in cardiothoracic surgery, simulator fidelity, transferability to the operating room environment, and local adoption remain challenges. The "Top Gun" competition, although intended to facilitate and motivate residents to practice and encourage facultyresident interaction using simulation, should not be construed as conferring technical proficiency. The synthetic simulator used in this study is of low fidelity, without the anatomic considerations in the operating room; importantly in a competitive setting, it is subject to "practicing to the test." The "Jeopardy" competition, whose purpose is to increase awareness and utilization of TSC, favors those who enjoy open contests and who are facile with brief questions with brief responses. Some residents may not enjoy such a setting and thus choose not to participate, thereby limiting the participation of some training programs. Its value in terms of assessing knowledge of cardiothoracic surgery should be interpreted in this context.

\section{CONCLUSIONS}

In an effort to increase the awareness of educators and trainees of the available educational tools and new curricula, such as simulation training and the TSC, a gamification approach focused on technical skills and cognitive competitions has been implemented in thoracic surgery training. This strategy is one framework to capitalize on the competitive nature of our trainees and provides recognition of their achievements.

\section{Conflict of Interest Statement}

Authors have nothing to disclose with regard to commercial support.

\section{References}

1. Vaporciyan AA, Yang SC, Baker CJ, Fann JI, Verrier ED. Cardiothoracic surgery residency training: past, present, and future. J Thorac Cardiovasc Surg. 2013; 146:759-67.
2. Connors RC, Doty JR, Bull DA, May HT, Fullerton DA, Robbins RC. Effect of work-hour restriction on operative experience in cardiothoracic surgical residency training. J Thorac Cardiovasc Surg. 2009;137:710-3.

3. Wall J. Millenium generation poses new implications for surgical resident education. American College of Surgeons. July 31, 2011. Available at: http:// www.facs.org/education/rap/wallo812.html. Accessed May 12, 2015.

4. Moffatt-Bruce SD, Ross P, Williams TE. American Board of Thoracic Surgery examination: fewer graduates, more failures. J Thorac Cardiovasc Surg. 2014; 147:1464-70.

5. Verrier ED. Joint Council on Thoracic Surgical Education: an investment in our future. J Thorac Cardiovasc Surg. 2011;141:318-21.

6. Goiten L, Shanafelt TD, Wipf JE, Slatore CG, Back AL. The effects of work-hour limitations on resident well-being, patient care, and education in an internal medicine residency program. Arch Intern Med. 2005;165:2601-6.

7. Fitzgibbons SC, Chen J, Jagsi R, Weinstein D. Long-term follow-up on the educational impact of ACGME duty hour restrictions: a pre-post survey study. Ann Surg. 2012;256:1108-12.

8. Lewis FR, Klingensmith ME. Issues in general surgery residency training. Ann Surg. 2012;256:553-9.

9. Kansier N, Varghese TK, Verrier ED, Drake FT, Gow KW. Accreditation Council for Graduate Medical Education case log: general surgery resident thoracic surgery experience. Ann Thorac Surg. 2014;98:459-64.

10. Nevin C, Westfall AO, Rodgriguez JM, Dempsey DM, Cherrington A, Roy B, et al. Gamification as a tool for enhancing graduate medical education. Postgrad Med J. 2014;90:685-93.

11. Schrope M. Solving tough problems with games. Proc Natl Acad Sci U SA. 2013; 110:7104-6.

12. Lee R, Enter D, Lou X, Feins RH, Hicks GL, Gasparri M, et al. The Joint Council on Thoracic Surgery Education coronary anastomosis too has high interrater reliability. Ann Thorac Surg. 2013;95:2064-9.

13. Fann JI, Caffarelli AD, Georgette G, Howard SK, Gaba DM, Youngblood P, et al. Improvement in coronary artery anastomosis with cardiac surgery simulation. $J$ Thorac Cardiovasc Surg. 2008;136:1486-91.

14. Enter DH, Lee R, Fann JI, Hicks GL, Verrier ED, Mark R, et al. "Top Gun” competition: motivation and practice narrows the technical skill gap among new cardiothoracic surgery residents. Ann Thorac Surg. 2015;99: 870-6.

15. American Board of Thoracic Surgery operative requirements. Available at: http:// www.abts.org/root/home/certification/operative-requirements.aspx. Accessed May 12, 2015.

16. Fann JI, Feins RH, Hicks GL, Nesbitt JC, Hammon JW, Crawford FA. Evaluation of simulation training in cardiothoracic surgery: the senior tour perspective. $J$ Thorac Cardiovasc Surg. 2012;143:264-72.

17. Ramphal PS, Coore DN, Craven MP, Forbes NF, Newman SM, Coye AA, et al. A high fidelity tissue-based cardiac surgical simulator. Eur J Cardiothorac Surg. 2005;27:910-6.

18. Fann JI, Calhoon JH, Carpenter AJ, Merril WH, Brown JW, Poston RS, et al. Simulation in coronary artery anastomosis early in cardiothoracic residency training: the boot camp experience. J Thorac Cardiovasc Surg. 2010;139: 1275-81.

19. Hicks GL, Gangemi J, Angona FE, Ramphal PS, Feins RH, Fann JI. Cardiopulmonary bypass simulation at the boot camp. J Thorac Cardiovasc Surg. 2011;141:284-92.

20. Papaspyros SC, Javangula KC, O'Regan DJ. Surgical training in the 48-h week: a novel simulation and education tool. From amateur golfer to professional pilot. Eur J Cardiothorac Surg. 2009;36:511-6.

Key Words: motivation, curriculum, internship and residency, learning, knowledge bases, achievement, thoracic surgery 